\title{
Effect of Polysorbate 80 \\ on Cell Leakage and Viability of Pseudomonas aeruginosa Exposed to Rapid Changes of $\mathrm{pH}$, Temperature and Tonicity
}

\author{
By M. R. W. BROWN AND B. E. WINSLEY \\ Pharmaceutical Microbiology Group, School of Pharmacy, \\ Bath University of Technology, Bath, Somerset
}

(Accepted for publication 4 December 1968)

SUMMARY

Leakage of $260 \mathrm{~m} \mu$-absorbing cell constituents from Pseudomonas aeruginosa was enhanced with increasing concentrations of Polysorbate 80 up to a characteristic maximum at $0.125 \%$. This relationship applied at $4^{\circ}, 18^{\circ}$ or $37^{\circ}$ at bacterial concentrations between $\mathrm{I} \times 10^{8}$ and $9 \times 10^{8} / \mathrm{ml}$. and for three strains of this organism, but did not apply with Escherichia coli. Uptake of a fluorescent dye was also greatest at $0.125 \%$ Polysorbate 80 . Increasing concentration of $\mathrm{NaCl}$ in the suspending liquid progressively decreased leakage. In buffer between $\mathrm{pH} 5 \cdot 7$ and $9 \cdot 5$, the low degree of leakage varied insignificantly. Polysorbate-treated organisms consistently leaked more readily and also showed greater percentage viability losses on rapidly changing the $\mathrm{pH}$, temperature or $\mathrm{NaCl}$ concentration of the suspending solution. There was little correlation between loss of viability and leakage. There was a correlation between loss of viability and the magnitude of the sudden change in any of the colligative properties of the organism's environment. Uptake of Polysorbate from aqueous solution at $20^{\circ}$ was rapid. These results supported the hypothesis that Polysorbate 80 had an immediate effect on the permeability barrier of the cell.

\section{INTRODUCTION}

Brown \& Richards (1964) showed that the non-ionic surface-active agent polyoxyethylene sorbitan mono-oleate (Polysorbate 80 ) enhanced the antibacterial activity of benzalkonium chloride, chlorhexidine diacetate and polymyxin-B sulphate. Polysorbate 80 acted synergistically with these agents on growth-rate inhibition and on lysis of Pseudomonas aeruginosa and Escherichia coli: this non-ionic agent alone had no observable effect on these phenomena.

The present work tests the hypothesis that Polysorbate 80 alters cell permeability. This was assessed by measuring the effect of Polysorbate 80 on the leakage of 260 $\mathrm{m} \mu(\mathrm{nm}$.)-absorbing substances(Salton, I95I ; Newton, I953; Hugo \& Longworth, 1964), on entry of a fluorescent dye (Newton, 1954) and on viability of bacteria under stress. Gorrill \& McNeil (1960) and Farrell \& Rose (1968) have reported the lethal effects of cold shock on Pseudomonas aeruginosa. This paper reports work on the effects of rapid changes of each of several colligative properties of the organisms environment. A brief report of part of this work has appeared previously (Brown \& Winsley, 1966). 


\section{METHODS}

Organisms and cultural conditions. The test organism was Pseudomonas aeruginosa NCTC 6750 . Stationary-phase pseudomonads were obtained by incubation at $37^{\circ}$ for $20 \mathrm{hr}$ in batch culture in nutrient broth (Oxoid, No. I: Oxo Ltd., London, S. E. I). Cell leakage experiments. Stationary-phase organisms were harvested by centrifugation at $20^{\circ}$ (M.S.E. refrigerated centrifuge, I4 Spenser St., London, S.W. I.) at $2500 \mathrm{~g}$, washed twice in $0.5 \mathrm{M}-\mathrm{NaCl}$ solution and finally suspended at $10^{8}$ to $10^{9}$ bacteria/ $\mathrm{ml}$. (0.06 to $0.6 \mathrm{mg}$. dry wt bacteria/ml.) in various aqueous solutions, including $\mathrm{NaCl}$, tris + maleate buffer (Geigy, I962), Polysorbate 8o (Crillet 4, Croda Ltd., Cowick Hall, Snaith, Goole, Yorkshire) and distilled water alone. Leakage was assessed by centrifuging at $20^{\circ}$ samples of the suspensions at $2500 \mathrm{~g}$ for $20 \mathrm{~min}$. and measuring the extinction at $260 \mathrm{~m} \mu(\mathrm{nm}$.) of the supernatant fluid with a Unicam S.P. 500 spectrophotometer, corrections being made for the extinction of the suspending solutions.

Effect of Polysorbate 80 on the optical effect of the organisms. The light-scattering properties of bacteria in suspension (measured as extinction at $600 \mathrm{~m} \mu$ ) alter with changes in environmental osmotic pressure; the ability of bacteria to show this alteration (the optical effect) may be regarded as a measure of the integrity of the osmotic barrier of the bacteria (Mager, Kuczynski, Schatzberg \& Avi-Dor, 1956; Postgate \& Hunter, I962).

Stationary-phase pseudomonads were grown in broth containing $0-0.175 \%$ Polysorbate 80; the bacteria from each culture were then washed and finally suspended separately in plain nutrient broth at a standard concentration; $0.05 \mathrm{ml}$. samples of each washed suspension were added to $3 \mathrm{ml}$. quantities of either nutrient broth or aqueous $\mathrm{NaCl}$ solutions $(0,0.1$ or $0.5 \mathrm{M})$. After $2 \mathrm{~min}$. at $20^{\circ}$, the extinction of each suspension was read at $600 \mathrm{~m} \mu$ against a reference cell containing the appropriate suspending liquid.

Effect of Polysorbate 80 on cell permeability to $\mathrm{I}$-anilinonaphthylamine-8-sulphonic acid $(A N S)$. Newton (1954) used the dye $N$-tolyl- $\alpha$-naphthylamine-8-sulphonic acid (TNS) to demonstrate the polymyxin-induced changes in the permeability of Pseudomonas aeruginosa. In the presence of polymyxin, the dye was able to penetrate to protein-containing parts of the organism, there to form a fluorescent conjugate. This technique was modified to investigate the effect of contact with Polysorbate 80 on cell permeability to a similar dye, ANS (Kodak Ltd., London).

Stationary-phase pseudomonads were cultured in nutrient broth containing $0-0.2 \%$ Polysorbate 80; the bacteria from each culture were washed and finally suspended separately at a standard concentration in aqueous $0.5 \mathrm{M}-\mathrm{NaCl}$ solution. A control suspension, completely permeable to ANS, was produced by heating at $100^{\circ}$ for 30 a sample of the washed suspension grown in polysorbate-free broth.

One ml. samples of the heated and unheated suspensions were each mixed with $3 \mathrm{ml}$. of $0.5 \mathrm{M}-\mathrm{NaCl}$ solution plus $2 \mathrm{ml}$. of $10^{-3} \mathrm{M}-\mathrm{ANS}$ in $0.5 \mathrm{M}-\mathrm{NaCl}$ solution. Appropriate bacteria-free blanks were also set up. The maximum fluorescence of each mixture in excitation light at $436 \mathrm{~m} \mu$ was measured in an Aminco-Bowman Spectrophotofluorimeter at $I 8^{\circ}$. Each suspension was re-read as above after removal of the bacteria by centrifugation at $2500 \mathrm{~g}$.

Viability experiments. A stationary phase culture was divided into two parts; the bacteria from one part were harvested, washed and suspended as above in saline, 
while bacteria from the other part were treated in the same way but nutrient broth replaced the saline. Total (chamber) counts were made (coefficient of variation $=4 \%$ ) on both final suspensions and showed that numbers differed insignificantly. Samples ( $0.1 \mathrm{ml}$.) of the saline suspension were added to $99.9 \mathrm{ml}$. of various suspending liquids held at various temperatures. Viability after dilution was assessed on $0.5 \mathrm{ml}$. samples taken at intervals, diluted in the same liquid and at the same temperature as that of the sample, and finally plated in triplicate on $10 \mathrm{ml}$. nutrient agar (Oxoid) spread plates, which were then incubated for $24 \mathrm{hr}$ at $37^{\circ}$ (coefficient of variation $=4.3 \%$ ). The initial $100 \%$ viability was taken as that of the saline suspension, diluted immediately in saline at $20^{\circ}$; the viability of the broth suspension was assessed after dilution with broth at $20^{\circ}$.

Uptake of Polysorbate 80 . Pseudomonads, harvested and washed in saline as above, were suspended at $5 \times 10^{8}$ bacteria/ml. in aqueous polysorbate 80 solutions at $20^{\circ}$. Samples, removed at intervals, were centrifuged to remove the bacteria. The supernatants were assayed for residual polysorbate by method II of Stevenson (I954).

Surface-tension measurements. The surface tension of solutions of Polysorbate 80 in either water or nutrient broth was assessed by using a de Noüy tensiometer with a $\mathrm{I} \mathrm{cm}$. diameter platinum wire ring in contact with the liquid surface. Readings for each solution were made at $\mathrm{I}$ min. intervals up to $\mathrm{I} 0 \mathrm{~min}$. at $18^{\circ}$.

\section{RESULTS}

\section{Effect of Polysorbate 80 on cell leakage}

Figure I shows the leakage patterns from bacteria grown in nutrient broth containing from zero to $0.15 \%$ Polysorbate 80 , washed, and suspended finally in water at $20^{\circ}$. The $260 \mathrm{~m} \mu$-absorbing constituents leaked out at rates decreasing with storage time, but increasing with concentration of polysorbate in the original culture: $0.13 \%$ polysorbate allowed the maximum leakage rate; above this concentration the rate decreased. The peak leakage concentration appeared to be $0.125 \%$, which is shown in Fig. 2: the leakage in $3 \mathrm{hr}$ into water at three temperatures was measured from bacteria grown in contact with 0 to $0.25 \%$ polysorbate. The relatively high leakage at $4^{\circ}$ correlated with the reported sensitivity of Pseudomonas aeruginosa to rapid cooling in water (Gorrill \& McNeil, 1960). The process of regulation of leakage may be an energy-requiring process (Hamilton, 1968) involving an enzyme system, which is inactivated by low temperatures (Meynell, I958) or rapid cooling (Farrell \& Rose, 1967).

The same relationship between leakage rate and polysorbate concentration occurred with bacteria grown in the absence of polysorbate, but stored for $3 \mathrm{hr}$ at $20^{\circ}$ in aqueous polysorbate solutions. The results were essentially the same as in Fig. 2 and the peak leakage concentration was again $0.125 \%$. This value was much higher than the critical micelle concentration (C.M.C.) of Polysorbate 80 in water (c. $0.001 \%$ : Vidal-Paruta \& King, 1964), but nevertheless within a concentration range $(0.05 \%$ to $0.3 \%$ ) producing greatest surface-tension depression, either in water or broth solution. Repeating this experiment separately with concentrations of $1 \times 10^{8}, 5 \times 10^{8}$ and $9 \times 10^{8}$ bacteria $/ \mathrm{ml}$. did not significantly alter the peak leakage concentration value of polysorbate 80 . This unexpected result could be explained in terms of lack of sensitivity of the technique to detect small changes in the peak leakage concentration. Alternatively, polysorbate 
micelles present may be of such a shape and size as to be able to affect more than one bacterium at the higher concentrations. Thus, to affect the permeability properties of the bacteria, polysorbate required neither an environment of salts (cf. the action of polymyxin, Newton, 1953) nor actively dividing bacteria. The leakage experiments were repeated using laboratory strains Pseudomonas aeruginosa CST 64 and $P$. aeruginosa osu 64. The peak leakage concentration and the pattern of leakage was the same for each strain, but the characteristic leakage rates differed. In contrast, leakage under these conditions from $E$. coli showed lesser leakage rates with a less well-marked peak at a lower polysorbate concentration.

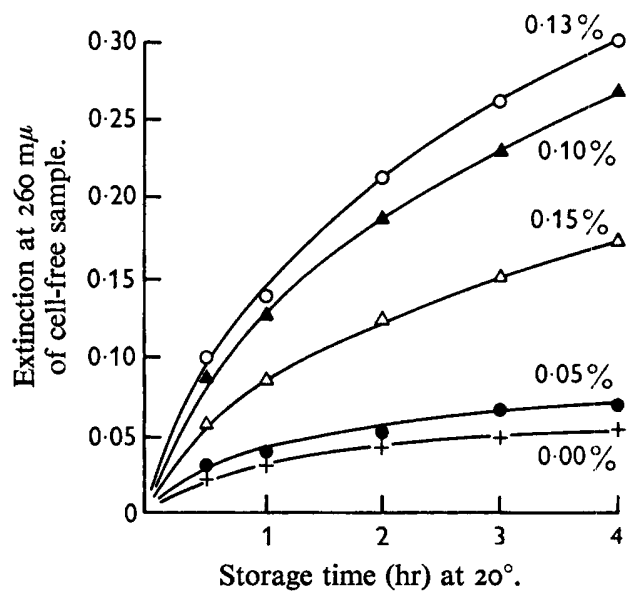

Fig. I

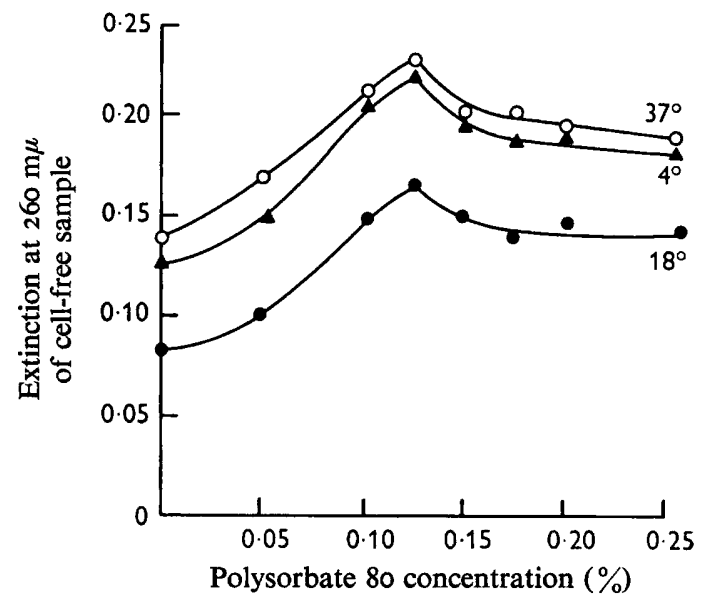

Fig. 2

Fig. I. $260 \mathrm{~m} \mu$ leakage during storage in water at $20^{\circ}$ of washed pseudomonads grown in presence of Polysorbate 80 (o to $0.15 \%$ ).

Fig. 2. $260 \mathrm{~m} \mu$ leakage during storage in water at $4^{\circ}, 18^{\circ}$ and $37^{\circ}$ of washed pseudomonads grown in presence of Polysorbate 80 (o to $0.25 \%$ ). Same relationship with a peak at $0.125 \%$ occurs for organisms grown in the absence of polysorbate but suspended in solutions as above.

Increasing the $\mathrm{NaCl}$ concentration in the suspension liquid of bacteria, grown without or with $0.1 \%$ polysorbate, progressively inhibited the leakage (Fig. 3). However, in each saline solution the bacteria previously exposed to polysorbate leaked more rapidly than the controls. These saline solutions ranged in $\mathrm{pH}$ from 5.8 (water) to $6 \cdot 2(2 \mathrm{M}-\mathrm{NaCl})$. There was relatively little leakage after storage for $4 \mathrm{hr}$ at $20^{\circ}$ in trismaleate buffer between $\mathrm{pH} 5.7$ and 9.5. At each $\mathrm{pH}$ the leakage was about the same as occurred after $4 \mathrm{hr}$ in $0.5 \mathrm{M}-\mathrm{NaCl}$ (Fig. 3). In every case polysorbate-exposed cells showed greater leakage.

\section{Effect of Polysorbate 80 on the Optical Effect of the Organisms}

Previous contact with polysorbate did not significantly alter the pronounced optical effect of the organisms at various $\mathrm{NaCl}$ concentrations. There was no optical effect with heat killed organisms.

The observed lack of influence on the optical effect by polysorbate may have been because there was relatively little viability loss by this treatment with $\mathrm{NaCl}$ solutions 
(Postgate \& Hunter, I962) and any alteration by polysorbate to the functioning of the cell's osmotic barrier was slight.

\section{Effect of Polysorbate 80 on the permeability to ANS}

The fluorescence of the bacteria, and therefore the amount of dye/protein conjugate, increased with polysorbate concentration in the growth medium up $0.125 \%$ (Table I). That fluorescence depended on the presence of bacteria and not only on leaked contents was shown by the 'after centrifugation' values which exceeded only slightly that of the blanks. Heat-killed bacteria were readily permeable to the dye. It seems unlikely that polysorbate would allow entry into the bacterium of ANS but cause no change in the optical effect. A possible explanation is that polysorbate alters the cell wall/membrane structure and allows uptake of ANS and combination with protein at this site.

Table I. Uptake of fluorescent dye by Pseudomonas aeruginosa after growth in broth with Polysorbate 80

The figures represent fluorescent-intensity as a percentage of intensity of a heated suspension

$\begin{gathered}\text { Polysorbate in } \\ \text { broth culture } \\ (\%)\end{gathered}$
0
$0 \cdot 01$
$0 \cdot 1$
$0 \cdot 125$
$0 \cdot 2$
Heated bacteria
Broth control
Blank control

$\begin{array}{cc}\begin{array}{c}\text { Before } \\ \text { centrifugation }\end{array} & \begin{array}{c}\text { After } \\ \text { centrifugation }\end{array} \\ 7 \cdot 4 & \text { I.I6 } \\ 8 \cdot 4 & \text { I.09 } \\ 9 \cdot 0 & \text { I.I } 6 \\ \text { I0.4 } & \text { I.20 } \\ \text { I0.0 } & \text { I.20 } \\ \text { I00 } & - \\ \text { I. I I } & \text { I.I I } \\ \text { I. I I } & \text { I.I I }\end{array}$

Uptake of Polysorbate 80 by the pseudomonads

A chemical assay (Stevenson, 1954) of polysorbate was used to study uptake by bacteria; a spectrophotometric assay for this substance, utilizing a u.v. extinction peak at $234 \mathrm{~m} \mu$ (Parker, Barnes \& Bradley, 1966), gave inconsistent results, influenced by the maker's batch of polysorbate. Uptake by organisms from aqueous polysorbate solutions was very rapid (Fig. 4) and was complete in 5 min., the minimum time taken to separate organisms by centrifugation. Although quicker separation of organisms and suspending solution was achieved by Millipore (Millipore (U.K.) Ltd., Heron House, 109 Wembley Hill Road, Wembley, Middlesex) membrane filtration, the uptake of polysorbate by the membrane was not found to be satisfactorily predictable.

\section{Effect of Polysorbate 80 on viability}

Gorrill \& McNeil (1960) reported loss of viability with Pseudomonas aeruginosa suddenly exposed to various aqueous solutions. Figure 5 shows a similar phenomenon occurring after sudden exposure to aqueous sodium chloride solutions. Solutions of $2 \mathrm{M}, 0.05 \mathrm{M}$ and $0.02 \mathrm{M}$ were also used, but have been omitted from the figure for clarity. The typical response involved an initial swift drop, followed by a more gradual one: $0.2 \mathrm{M}$ and $0.5 \mathrm{M}-\mathrm{NaCl}$ caused similar, minimal losses of viability (Fig. 6). 
In each case organisms previously exposed to polysorbate showed greater viability losses. $0.5 \mathrm{ml}$. of $4 \mathrm{M}-\mathrm{NaCl}$ solution spread over and absorbed by an agar plate was not inhibitory to the growth of organisms spread subsequently over the plate. Comparison with the viability of bacteria washed and suspended in broth showed that the washing process with $0.5 \mathrm{M}$-saline had reduced viability by about $20 \%$.

Figure 7 illustrates a similar phenomenon. Organisms, washed and suspended in $0.5 \mathrm{M}-\mathrm{NaCl}$ solution at $20^{\circ}$, were suddenly exposed to $0.5 \mathrm{M}-\mathrm{NaCl}$ solution at

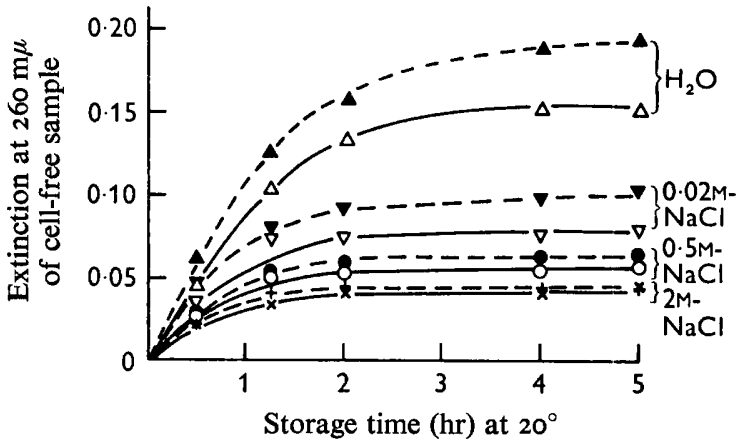

Fig. 3

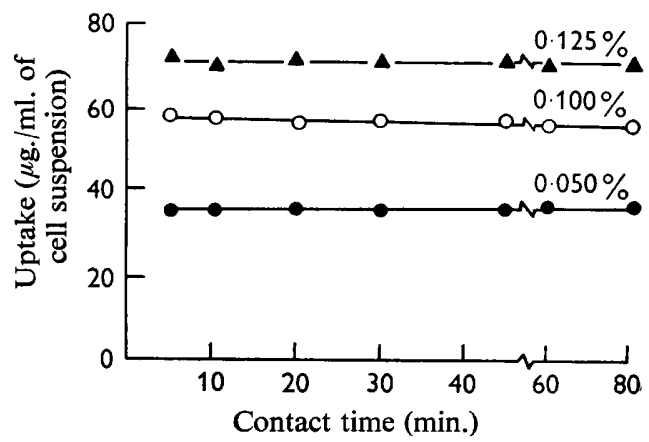

Fig. 4

Fig. 3. $260 \mathrm{~m} \mu$ leakage during storage at $20^{\circ}$ in water or aqueous sodium chloride solutions of washed pseudomonads grown in presence or absence of Polysorbate 80. - - , Organisms grown in broth; -- -, organisms grown in broth $+0.1 \%$ Polysorbate 80 .

Fig. 4. Uptake at $20^{\circ}$ of Polysorbate 80 from its aqueous solutions $(0.05,0.10$ or $0.126 \%$ by suspensions of washed pseudomonads grown in absence of Polysorbate 80.

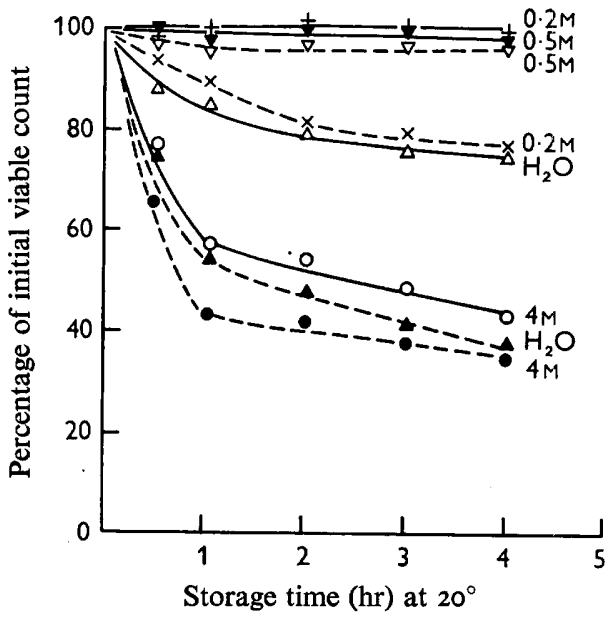

Fig. 5

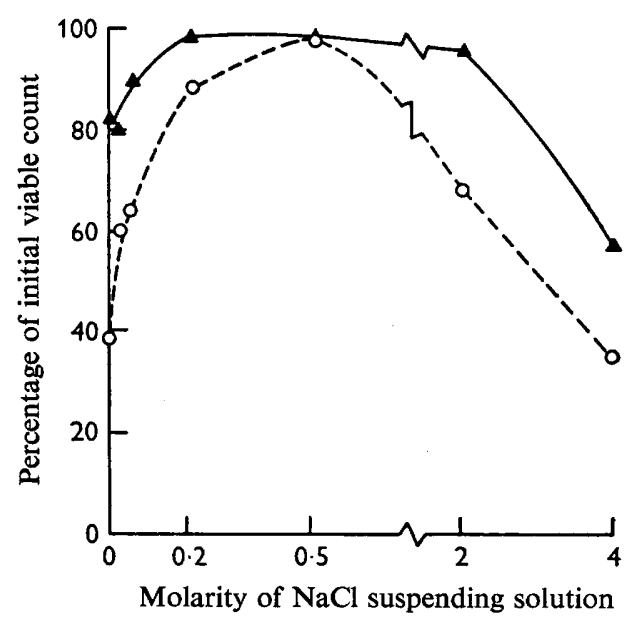

Fig. 6

Fig. 5. The effect at $20^{\circ}$ on the viability of washed pseudomonads, grown in presence or absence of Polysorbate 80 , of sudden exposure to and storage in water or aqueous sodium chloride solutions $(0.2,0.5$ or $4 \mathrm{M})$.- - Organisms grown in broth; - - -, organisms grown in broth $+0.1 \%$ Polysorbate 80 .

Fig. 6. The effect on the viability of washed pseudomonads grown in presence or absence of Polysorbate 80 , of sudden exposure to and storage for $\mathrm{I} \mathrm{hr}$ at $20^{\circ}$ in various sodium chloride solutions or in water. - - Organisms grown in broth; - - , organisms grown in broth + $0.1 \%$ Polysorbate 80 . 
temperatures between $20^{\circ}$ and $40^{\circ}$. Viabilities were assessed on samples after $30 \mathrm{~min}$., $2 \mathrm{hr}$ and $4 \mathrm{hr}$ storage of organisms exposed during growth to $0 . \mathrm{I} \%$ polysorbate and of controls, Greatest kill correlated with the greatest sudden temperature increase.

A similar experiment involved organisms shocked by sudden exposure to trismaleate buffer at between $\mathrm{pH} 5.7$ and 8.8 (Fig. 8). Least loss of viability occurred at $\mathrm{pH} 7 \cdot 4$ and, in each case, organisms previously exposed to polysorbate were more susceptible.

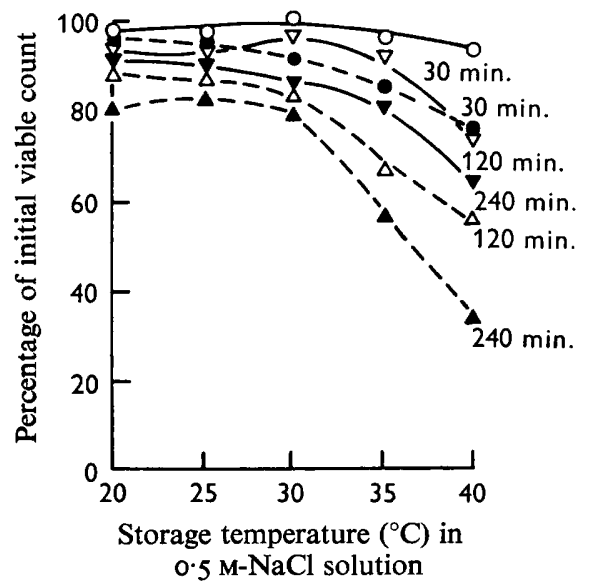

Fig. 7

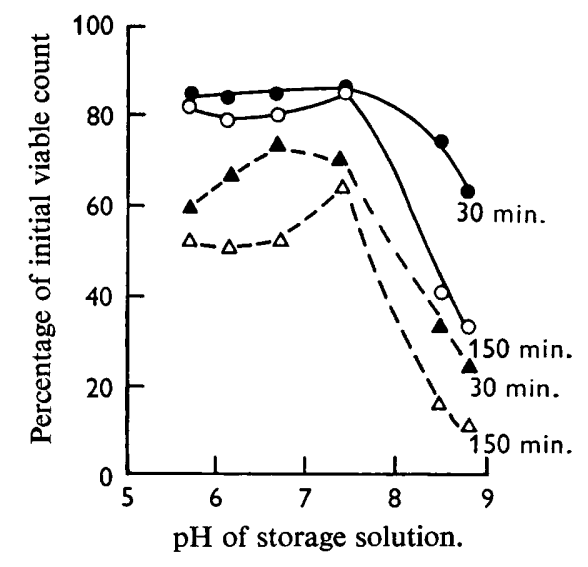

Fig. 8

Fig. 7. The effect on the viability of washed pseudomonads, grown in presence or absence of Polysorbate 80 , of sudden exposure to and storage for 30,120 or $240 \mathrm{~min}$. in $0.5 \mathrm{M}$-sodium chloride solution at various temperatures. - Organisms grown in broth; - - -, organisms grown in broth $+0.1 \%$ Polysorbate 80 .

Fig. 8. The effect on viability of washed pseudomonads grown in presence or absence of Polysorbate 80 , of sudden exposure to and storage for 30 and $150 \mathrm{~min}$. in tris-maleate buffer at $20^{\circ}$. - Organisms grown in broth; - - , organisms grown in broth $+0.1 \%$ Polysorbate 80 .

\section{DISCUSSION}

The loss by leakage of constituents, including the $260 \mathrm{~m} \mu$-absorbing purine and pyrimidine compounds, from bacteria exposed to surface-active agents is well known, and the pattern, showing a peak leakage concentration of agent, has been reported for several cationic agents (Salton, 195I; Newton 1953; Hugo \& Longworth, 1964). In the present work, a non-ionic agent has caused a similar effect. With Pseudomonas aeruginosa the characteristic peak leakage concentration of the agent was the same at temperatures of $4^{\circ}, 18^{\circ}, 20^{\circ}$ and $37^{\circ}$ and at three concentrations of organisms. Contact with the agent during growth of the pseudomonads in broth or during subsequent storage in aqueous polysorbate solutions gave the same leakage patterns (Fig. 2). Polysorbate did not alter the optical effect and this result suggests that there is only a relatively subtle effect on the osmotic barrier of these bacteria. The growth rate of $P$. aeruginosa does not vary in nutrient broth containing polysorbate within the concentration range used in this work, suggesting an absence of any gross change in the osmotic barrier. The technique of using penetration of ANS showed contact with $0.125 \%$ polysorbate to cause greatest uptake (Table I) and this concentration of the surfactant in fact also caused the maximum outflow of $260 \mathrm{~m} \mu$ - 
absorbing substances (Fig. 2). Hugo \& Longworth (1964) suggested that chlorhexidine, especially above its peak leakage concentration, caused extensive denaturation of the protein and gross cytoplasmic disorganisation. Similar protein-precipitating effects occurred with a polyalkylbiguanide (Davies \& Field, 1967). These effects may possibly have contributed to both loss of viability and the fall-off in leakage observed, but it is unlikely, since non-ionics have little denaturing action on proteins (Putnam, I953). The uptake of polysorbate is presumably via hydrogen bonding: Hamilton (I968) considered that the adsorption by organisms of membrane-active antibacterial agents was via a relatively non-specific physico-chemical phenomenon. Once bound, polysorbate alters the permeability properties of the organisms and increased leakage was observed immediately after adding the surfactant. These results indicated a direct physical action, rather than one involving permease-inhibition or stimulation of autolytic enzymes, and are consistent with the hypothesis that polysorbate has an immediate effect on the organisms permeability regulation system. Such a physical effect may involve interference by the surfactants with the packing or molecular organization within the membrane or membrane/wall envelope of these Gram-negative organisms.

Cell-membrane disorganization would allow an enhanced interchange of molecules and ions between the internal and external environments of the bacterium. Non-ionic agents caused reduced electrostatic resistance and increased cation permeability of reconstituted lipid-membrane preparations (Seufert, 1965). Thus, loss of viability may be the consequence of two processes: (i) the loss of vital cell constituents, including purine and pyrimidine compounds, which reflects degradation of cellular RNA (Holden, 1958; Postgate, 1967), (ii) gain of substances normally not present or in strictly limited amounts.

The outflow of $260 \mathrm{~m} \mu$-substances was decreased when the organisms were suspended in saline or buffer solutions (Fig. 3). Other pseudomonads also showed less lysozymeinduced damage to the wall/membrane structure when suspended in saline solutions (Shively \& Hartsell, 1964). However, viability losses in these solutions were still marked and therefore no correlation existed between degree of kill and loss of $260 \mathrm{~m} \mu$ substances. There was a correlation between degree of kill and the magnitude of the sudden change in any of the colligative properties of the organism's environment. Although this type of effect is well known, especially with cold shock (Gossling, 1958; Meynell, 1958; Gorrill \& McNeil, 1960), previous exposure to polysorbate aggravated the viability loss for any given abrupt change.

We are grateful to the Medical Research Council for a grant which supported this work.

\section{REFERENCES}

Brown, M. R. W. \& Richards, R. M. E. (I964). Effect of Polysorbate 80 on the resistance of Pseudomonas aeruginosa to chemical inactivation. J. Pharm. Pharmac. 16 (Suppl.), 5I T.

Brown, M. R. W. \& Winsley, B. E. (1966). The effect of Polysorbate 80 on cell leakage of Pseudomonas aeruginosa. J. gen. Microbiol. 45. iv.

DAVIES, A. \& Field, B. S. (1967). The bactericidal action of biguanides. Biochem. J. 106, 46.P

FARrell, J. \& Rose, A. H. (1967). Temperature effects on micro-organisms. In Thermobiology. Ed. by A. H. Rose, p. 142. London: Academic Press.

FARrell, J. \& Rose, A. H. (1968). Cold shock in a mesophilic and a psychrophilic Pseudomonad. J. gen. Microbiol. 50, 429. 
GeIGY, (1962). Documenta Geigy Scientific Tables, 6th ed., p. 314. Manchester: Geigy Pharmaceutical Publishing Co. Ltd.

GORRILL, R. H. \& McNeIL, E. M. (1960). The effect of cold diluent on the viable count of Pseudomonas pyocyanea. J. gen. Microbiol. 22, 437.

GossLING, B. S. (1958). The loss of viability of bacteria in suspension due to changing the ionic environment. J. appl. Bact. 2 I (2), 220.

HAMILton, W. A. (1968). The mechanism of the bacteriostatic action of tetrachlorosalicylanilide: a membrane-active antibacterial compound. J. gen. Microbiol. 50, $44 \mathrm{I}$.

HoLDEN, J. T. (1958). Degradation of intracellular nucleic acid and leakage of fragments of Lactobacillus orabirosus. Biochem. biophys. Acta 29, 667.

Hugo, W. B. \& Longworth, A. R. (1964). Some aspects of the mode of action of chlorhexidine. $J$. Pharm. Pharmac. 16, 655.

MAGER, J., KuCZYNSKI, M., SChATZBerg, G. \& Avi-Dor, Y. (1956). Turbidity changes in bacterial suspensions in relation to osmotic pressure. J. gen. Microbiol. 14, 69.

MeYNeLl, G. G. (1958). The effect of sudden chilling on Escherichia coli. J. gen. Microbiol. 19, 380.

Newton, B. A. (1953). The release of soluble constituents from washed cells of Pseudomonas aeruginosa by the action of polymyxin. J. gen. Microbiol. $9,54$.

NewTON, B. A. (1954). Site of action of polymyxin on Pseudomonas aeruginosa: antagonism by cations. J. gen. Microbiol. ro, 49I.

Parker. M. S., Barnes, M. \& Bradley, T. J. (I966). The use of the Coulter Counter to detect the inactivation of preservatives by a non-ionic surface-active agent. J. Pharm. Pharmac. 18, 103 S.

Postgate, J. R. (1967). In Advances in Microbiol Physiology. Ed. by A. H. Rose and J. F. Wilkinson. Vol. I, pp. I. London: Academic Press.

Postgate, J. R. \& Hunter, R. (1962). The survival of starved bacteria. J. gen. Microbiol. 29, 233.

Putnam, F. W. (1953). In Proteins. Ed. by H. Neurath and K. Bailey. Vol. I B, p. 817. New York: Adademic Press.

Salton, M. R. J. (195I). The adsorption of cetyltrimethylammonium bromide by bacteria, its action in releasing cellular constituents and its bactericidal effects. J. gen. Microbiol. 5, 39I.

SEUFERT, W. D. (1965). Induced permeability changes in reconstituted cell membrane structures. Nature, Lond. 207, 174.

Shively, J. M. \& HARTSELl, S. E. (1964). Bacteriology of the pseudomonads. II. Chemical treatments affecting the lytic response. Can. J. Microbiol. ro, $9 \mathrm{I}$ I.

SteVenson, D. G. (1954). Assay methods for non-ionic surface-active agents. Analyst, Lond. 79, 504.

Vidal-Paruta, M. R. \& KING, L. D. (1964). Critical micelle concentration of non-ionic surfactants in water and carbon tetrachloride. J. pharm. Sci. 53 (10), 1217. 